\title{
LA LEYENDA DE LA CASA DEL INFIERNO ANÁLISIS DE UNA ADAPTACIÓN
}

\author{
IVÁN GÓMEZ \\ Universitat Ramon Llull \\ ivangg@blanquerna.url.edu \\ Recibido: 15-01-2014 \\ Aceptado: 15-05-2014

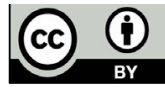

\section{RESUMEN}

Richard Matheson ha sido un escritor popularmente conocido por sus obras de corte fantástico o por sus brillantes incursiones en la ciencia ficción. No obstante, su extensa producción literaria y audiovisual ha transitado todos los géneros, desde el western hasta la comedia, y varios formatos audiovisuales. En este artículo nos centraremos en algunas obras estrechamente vinculadas a lo fantástico y, más concretamente, en la novela La casa infernal, indagando cómo el autor construye los espacios psíquicos y físicos habitados por los personajes. Espacios infernales, inhóspitos e inhabitables son transitados por sujetos problemáticos o inadaptados que tratan de sobrevivir a fuerzas que exceden sus capacidades de comprensión. El objetivo del artículo es adentrarse en esta adaptación a partir de algunas categorías vinculadas con el discurso científico que nos permitan orientarnos en una obra inabarcable y excesiva y que, en gran medida, está todavía por estudiar.

PAlabras Clave: Matheson, cine, televisión, horror, adaptación.

ABSTRACT

Richard Matheson has been a writer popularly known either for his works of the fantastic and horror or for his brilliant forays into science fiction. However, his extensive literary and audiovisual production has embraced all genres, from westerns to comedy, as well as various audiovisual formats. In this article we will focus on some work closely related to the fantastic, horror and science fiction, particularly on the novel Hell House, and we will analyse how the author constructs the mental and physical spaces inhabited by the characters. Often troublesome or marginalised subjects usually 
try to survive forces that exceed their understanding in these infernal, inhospitable and uninhabitable spaces. The aim of this article is to explore this film adaptation adaptation of Hell House by means of some categories related to the scientific discourse. These categories will allow us to orient ourselves in a boundless and excessive work and that largely remains to be studied.

KEYWORDS: Matheson, cinema, television, horror, adaptation.

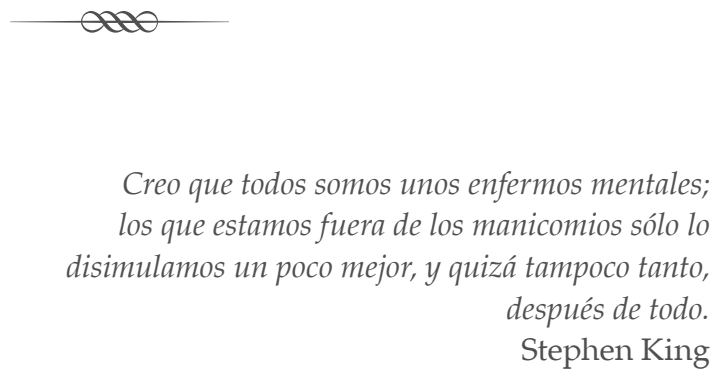

Soy un narrador. La historia es lo que importa. Pueden ponerlo en mi lápida: narrador.

Richard Matheson

\section{El oscuro mundo de Richard Matheson}

Partamos de una afirmación que no por obvia es menos cierta. El universo narrativo de Richard Matheson es tan extenso e intenso que resulta complicado aproximarse a él sin caer en una excesiva parcialidad o en el comentario impresionista. Estamos hablando de un autor que ha trabajado el cuento, la novela, el guión de cine y el guión de televisión, multiplicando las versiones de sus historias, adaptándolas a diferentes medios y ubicándolas dentro de diversos géneros, si bien una parte importante de su producción se adentra en los territorios de lo fantástico y la ciencia ficción. ${ }^{1}$ Matheson conoció la primera auténtica edad dorada del género fantástico, vivió el largo y fructífero invierno de la ciencia ficción alegórica de los cincuenta y

1 En una extensa e interesante entrevista que Richard Matheson concedió al crítico Pat McGilligan reconoció que en un primer momento no tenía ni idea de que estaba escribiendo historias de ciencia ficción hasta que alguien se lo dijo. Eso fue unos años antes de vender sus historias y guiones a programas de televisión como el mítico The Twilight Zone (CBS, Rod Serling, 1959-1964). En McGilligan (2003: 200). 
ayudó a construir el canon televisivo norteamericano de finales de esa década y principios de los sesenta. En este sentido si está cerca de otro autor es de ese gigante de las letras que fue Ray Bradbury, con el que compartió innumerables intereses. Es posible que con el tiempo las grandes historias de la literatura norteamericana reconozcan a estos autores en términos preferentes, lugar que sin duda merecen no sólo por sus grandes ideas, sino por su firme ejecución. Lo que sitúa a Bradbury y a Matheson a la altura de un Richard Yates o un Don DeLillo es su estilo, no únicamente sus brillantes ideas fantásticas.

Hecha esta consideración previa, ¿podemos citar alguna categoría que nos ayude a trazar una primera aproximación a la obra de Matheson que es el objeto de estudio preferente de este artículo? Nos hemos propuesto analizar la novela de Richard Matheson Hell House (La Casa Infernal, 1971) y su posterior adaptación al cine, que data de 1973. Novela y película aparecen en un momento de renacimiento del género a nivel cinematográfico y se incardinan bien en la tradición que había hecho de las mansiones encantadas un espacio infernal privilegiado, particularmente adecuado para excitar la imaginación de lectores y espectadores. Una tradición explicada en ocasiones dentro de la muy extensa y algo imprecisa etiqueta American Gothic, que Matheson tiene muy presente a la hora de escribir La Casa Infernal, una novela plagada de momentos terroríficos y profundamente impactantes incluso para un lector acostumbrado a este tipo de ficciones.

Precisamente ahí podríamos arrancar nuestro análisis. Si por algo es conocido Richard Matheson es por su capacidad para la sorpresa, a menudo formulada como un giro final dentro de una historia corta, recurso que hizo célebres muchos de los relatos y adaptaciones audiovisuales que realizó para la conocida serie de televisión The Twilight Zone (CBS, Rod Serling, 1959-1964). Matheson es un autor que tiene al lector muy presente, se preocupa por sus reacciones, sabe manipular la expectativa lectora, y es capaz de alterar o sobresaltar al lector aunque utilice un material ya conocido o incluso manido, como pueda ser una historia de casas encantadas. Esto debería hacernos reflexionar sobre la naturaleza de ese efecto en el lector, esa inquietud o terror que puede sentir ante historias que, de alguna manera, ya conoce previamente porque las ha consumido en otros lugares. ¿Por qué sigue siendo efectiva una historia como La Casa Infernal? ¿Por qué sigue inquietando el relato «Pesadilla a 20.000 pies»? ¿Qué tienen estos relatos que siguen produciendo un intenso horror tantos años después de ser escritos? Por supuesto la respuesta tiene que ver con el concepto de «lo fantástico», elemento que está en la base 
de nuestra aproximación y a la que vamos a intentar añadir algún matiz adicional.

Probemos con un concepto científico. Pensemos por un momento en la categoría de la ausencia, utilizada por el profesor Terrence W. Deacon en su estudio Naturaleza incompleta. El profesor Deacon nos advierte de algo que una parte importante del estamento científico afirma sin demasiado entusiasmo: que a pesar del nivel de desarrollo científico hay demasiadas cosas que todavía no sabemos y que todavía no pueden ser explicadas, cosas, por otro lado, muy próximas a nuestro entorno cotidiano. La consciencia, por ejemplo,

siempre es un fenómeno residual que permanece inexplicado una vez se han descrito todos los procesos físicos correlacionados. [...] Como los significados y los propósitos, las consciencias pueden no estar ahí en ningún sentido físico típico de encarnación material o energética, y aun así seguir siendo relevantes a efectos materialmente causales (Deacon, 2012: 21).

Consciencia, significados y propósitos serían tres cuestiones pendientes de completa explicación científica. Por mucho que en nuestra vida diaria los significados y propósitos se den por sentado, recuerda Deacon (2013: 23), no los hemos descodificado completamente porque en las ciencias de la vida y de la mente sólo parece que estemos dispuestos a admitir lo que está materialmente presente. La ciencia sigue indagando el porqué de algunas cuestiones fundamentales y en los últimos años hemos llegado a ciertas conclusiones provisionales. Por ejemplo, sabemos que la inmensa mayoría de nuestro pensamiento es inconsciente y que nuestra comprensión del mundo no se produce por el trabajo de un circuito que de manera activa reproduce perfectamente lo que ve. Antonio Damasio es claro al respecto: las imágenes mentales correspondientes de los objetos y acontecimientos fuera del cerebro «son creaciones de éste relacionadas con la realidad que provoca su creación, y no imágenes especulares pasivas que reflejan la realidad» (2005: 89). ${ }^{2}$

Así que carecemos de un modelo heurístico que pueda explicar por completo fenómenos aparentemente tan estudiados por la ciencia como la intencionalidad. Bien podríamos concluir que existe una auténtica zona oscura, indefinida y de contornos poco claros, en la que todo puede suceder (o

2 De manera similar podrían pronunciarse otros neurobiólogos, antropólogos y médicos que han estudiado en los últimos años el fenómeno de la mente. Entre ellos Eric Kandle, Francisco Mora o Vilayanur Ramachandran. 
casi) mientras no sepamos exactamente qué es posible y qué no, y es precisamente en esa zona de indefinición en la que viven y se desarrollan gran parte de los relatos fantásticos de Richard Matheson -y también los de ciencia ficción, claro, terreno abonado para la pura especulación de corte científico-. Como autor, Matheson ve donde el ser humano deja de ver. Escribe sobre los límites de lo comprensible y de lo aceptable, sabedor de que todo aquello que no podemos ver, entender y descodificar no puede ser aceptado por el ser humano. Y en esa zona oscura, donde el modelo heurístico falla y se plantea una ausencia, se desarrollan los mejores relatos del escritor estadounidense.

Esta categoría, la ausencia, guarda una estrecha relación con los conceptos de lo fantástico y el novum, lo que se estaría en la base de la articulación del discurso de los relatos fantásticos por un lado y de los de ciencia ficción por otro. Sabemos que lo fantástico surge de la mezcla conflictiva entre lo real y lo imposible y que «la condición de imposibilidad del fenómeno fantástico se establece, a su vez, en función de la concepción de lo real que manejan tanto los personajes como los receptores» (Roas, 2011: 45). En ese choque establecemos la irrupción de lo fantástico dentro de la ficción, si bien podríamos establecer una precisión importante a partir del concepto de disonancia cognitiva, particularmente importante en los relatos de Matheson. Es cierto que lo fantástico plantea elementos imposibles dentro de entornos cotidianos y reconocibles, si bien no siempre los personajes de los relatos lo perciben como imposible -y no estamos aquí hablando de otra categoría, lo maravilloso-. En La Casa Infernal, por ejemplo, dos de los personajes son médiums (uno físico y otro psíquico), de tal manera que en su particular mundo la irrupción del demonio o un caso de posesión son perfectamente posibles (da igual si son más o menos improbables). En este caso la disonancia cognitiva, ese desajuste entre la realidad y la irrupción del elemento perturbador, no se da en los personajes, sino en los lectores que saben que esos casos son perfectamente imposibles porque no ajustan con la visión del mundo que les rodea. Y aquí es donde debemos añadir un pequeño elemento que nos plantea ciertas dudas. Estos hechos pueden ser imposibles, efectivamente, pero y si... La disonancia cognitiva en el lector no puede ser completa y absoluta, porque siempre existe esa cláusula de cierre, la remota duda sobre si fenómenos tan improbables como el demonio o los fantasmas podrían llegar a existir. No deja de ser una buena manera de provocar la irrupción del horror en los relatos fantásticos y en parte de la obra de Matheson ese extremo puede apreciarse bien, por cuanto el autor es perfectamente 
consciente de ese margen de indefinición que rodea el universo de las explicaciones científicas. ${ }^{3}$

Quizás podamos añadir otra vía más de aproximación a la obra de Matheson que permita establecer un primer puente con las algunas de sus obras. No son pocos los relatos que el autor sitúa en espacios cotidianos transmutados en auténticos infiernos en los que los personajes se acaban perdiendo psíquicamente. Los infiernos en Matheson tienen una entidad física y material muy precisa, pero no destruyen el cuerpo de los personajes, sino su mente. Algunos de estos personajes acaban viviendo esos espacios como lugares imposibles de los que nunca más regresarán sanos y salvos. Espacios que, además, son muy diversos. En «La Casa Slaughter», por ejemplo, asistimos a un relato de casa encantada al más puro estilo American Gothic, mientras que en «Pesadilla a 20.000 pies» el horror ha escalado hasta el ala de un moderno avión. ${ }^{4}$ En Matheson lo geográfico y lo psicológico van cogidos de la mano, son dos caras de una misma moneda. En numerosas ocasiones el horror más extremo puede habitar en nuestro interior, como una fuerza oculta que pugna por salir y manifestarse, en combinación o no con el horror que viene de fuera. Es por ello que parte de la obra de Matheson puede estudiarse y ser definida como una exploración constante de esa magnitud tan compleja que es el yo, siempre en formación y con abundantes zonas de sombra. Como si de un científico se tratase, Matheson utiliza esa indefinición que acompaña al concepto de yo para jugar con él y convertirlo en la parte central del problema narrativo que exhibe en diferentes ficciones.

En consonancia con el concepto de ausencia que explicábamos a propósito de la obra de Deacon, debemos explorar estas palabras de Douglas Hofstadter (2008: 128-129):

en un cerebro humano desarrollado existe un tipo especial de estructura abstracta o patrón [...] la criatura atribuye su comportamiento a cosas que refiere como sus deseos o apetencias, pero no puede decir exactamente por qué los

3 Seguramente por ello la nómina de actividades que el lector puede experimentar frente a estos relatos fantásticos incluye: «Supposition, hypothesis, assumption, presumption, ignorance, prejudice, optimism, insecurity, anxiety - all of these features and countless others can shape our view of the world» (Walters, 2011: 96). Stanley Cavell también se pronuncia sobre esta cuestión: «It is a poor idea of fantasy which takes it to be a world apart from reality, a world clearly showing its unreality. Fantasy is precisely what reality can be confused with. It is through fantasy that our conviction of the worth of reality is established; to forgot our fantasies would be to forgot our touch with the world. And does someone claim to know the specific balance sanity must sustain between the elaborating demands of self and world, some neat way of keeping soul and body together?» (1979: 85).

4 El primer relato fue publicado en Weird Tales en julio de 1953, el segundo forma parte del conjunto de relatos que lleva por título Alone by night, Michael \& Don Congdon, ed., Ballantine, Nueva York, 1962. 
tiene. Llegados a cierto punto, no cabe un ulterior análisis o una ulterior explicación [...] Y siempre, en todas las frases que expresan por qué hace lo que hace, está el pronombre «yo», explícita o tácitamente.

Así que incluso en algo tan sagrado como el yo, su formación, atributos y funcionamiento, hay un margen de indefinición descrito científicamente. Pues bien, por esa grieta científica se cuelan buena parte de los relatos de Matheson, tanto los fantásticos como los de ciencia ficción, y de manera muy clara su novela La Casa Infernal presentada como un auténtico informe científico que pretende desentrañar los misterios de lo que Stephen King ha llamado el Mal Lugar. ${ }^{5}$

Ese yo, entidad problemática e inestable, es el encargado de construir y entender dos magnitudes centrales en las que vivimos nuestras vidas, el tiempo y el espacio. Dos magnitudes cuyas alteraciones e irregularidades constituyen buena parte de la base sobre la que se construyen igualmente los relatos de Richard Matheson, desde los capítulos que escribió para The Twilight Zone hasta sus conocidas novelas Bid Time Return (En algún lugar del tiempo, 1975) o What Dreams May Come (Más allá de los sueños, 1978).

\section{TEORÍA DE LA MANSIÓN ENCANTADA}

Vamos a transitar por unos momentos por uno de los lugares favoritos del American Gothic, la casa encantada. No deja de ser curioso que un escritor ya en su etapa de madurez creativa elija para una de sus obras mayores el motivo, repetido y ya muy tratado en la literatura fantástica norteamericana, de la mansión encantada. ${ }^{6}$ La historia de La Casa Infernal arranca un 18 de diciembre de 1970 a las 3:17 P.M., y ese detalle no resulta casual. Toda la novela estará fechada y perfectamente datada, de manera que la narración acaba presidida por la lógica del informe científico, o acaso policial. En el fondo se nos presenta un caso y se hace combinando una cierta frialdad expositiva con un estudio psicológico detallado y mucho menos aséptico de unos personajes

5 La idea del informe científico, de la investigación por parte de científicos parapsicólogos, ha articulado recientemente una apreciable película con casa encantada de por medio, The Conjuring (James Wan, 2013), traducida aquí como Expediente Warren. Por su parte Stephen King habla del Mal Lugar en su ensayo Danza Macabra como un tópico de la literatura gótica norteamericana que se concreta en espacios tan amenazantes como las casas encantadas.

6 Con todo deberíamos precisar aquí que justo en esos momentos el motivo de la mansión encantada estaba siendo sometido a severa revisión por parte de escritores como Shirley Jackson y que algunas de las grandes películas sobre casa encantadas estaban aún por llegar. La adaptación de la novela de Shirley Jackson The Haunting of Hill House (1959) originó la celebrada The Haunting (Robert Wise, 1963), y aún estaban por llegar obras como Terror en Amityville (Stuart Rosenberg, 1979). 
que acuden a la casa movidos por intereses diversos. La casa Belasco se alza amenazante y altiva, a la espera de los siguientes viajeros que se atrevan a adentrarse en ella. Como toda buena casa encantada la casa Belasco arrastra una historia luctuosa ya que en 1940 un grupo de cinco personas se enfrentó a ella para intentar demostrar la existencia del más allá. Sólo una persona sobrevivió, un hombre llamado Fischer, que treinta años después se dispone a entrar de nuevo en el infierno.

El objetivo de la expedición vuelve a ser científico, en este caso. El líder de la expedición, el doctor Barrett, será el encargado de demostrar que existe un más allá y que el mundo no está únicamente constituido por lo que vemos o podemos medir. En este sentido la novela de Matheson contiene un motor narrativo parecido al de la novela de Shirley Jackson, The Haunting of Hill House (1959), adaptada al cine en 1963 por Robert Wise. En la obra de Jackson es el Dr. Montague quien busca pruebas de la existencia de lo sobrenatural, sin saber bien qué se va a encontrar al otro lado del espejo. Ambas casas respetan bien los patrones que debe tener una buena casa encantada. Debe ser más grande por dentro que por fuera, tener una presencia ominosa y arrastrar historias truculentas y horrorosas. La casa encantada es un espacio auténticamente infernal, la puerta de entrada a lo demoníaco, el punto de acceso que personajes curiosos pueden utilizar para entrar en el infierno, pero también el punto que los demonios pueden utilizar para salir de su encierro. La delimitación física y el establecimiento de una topografía definida son elementos necesarios de una casa encantada. ${ }^{7}$ Es un infierno con límites, en donde el primer concepto que queda alterado es el del espacio. En La Casa Infernal Matheson dibuja una casa de contornos imprecisos que se convierte en un espacio amenazante capaz de alterar el estado mental de sus moradores. Dice Stephen King (2006: 106):

Todos los cuentos de horror pueden dividirse en dos grupos: aquellos en los que el horror es consecuencia de un acto de propia y libre voluntad (una decisión consciente de cometer el mal) y aquellos en los que el horror está predestinado y llega desde el exterior como un relámpago.

Apostilla King (2006: 107) que las historias en las que el horror proviene del exterior son más difícilmente creíbles si bien «el concepto del mal ex-

7 Esta divertida idea, la de una casa más grande por dentro que por fuera, es citada a menudo por el autor de La casa de hojas, Mark Z. Danielewski, como el elemento que le permitió iniciar su celebrada novela. Tampoco debemos olvidar que la obra de Danielewski también contiene la idea del informe científico, en este caso convertido en un documental que uno de los personajes de la historia rueda sobre la mítica casa encantada. 
terno tiene más alcance, es más impresionante. Lovecraft así lo entendió, y es lo que hace sus historias de extraordinaria, ciclópea maldad tan efectivas cuando son buenas». Realmente en La Casa Infernal los protagonistas se enfrentan a un mal exterior, los espíritus malignos que moran en la casa Belasco. Los cuatro componentes de la expedición se enfrentan a una fuerza desconocida y demoníaca que ya anteriormente demostró su peligrosidad. La expedición la componen el Dr. Lionel Barrett (interpretado por Clive Revill en la versión fílmica), su esposa Edith (Ann en la película, interpretada por Gayle Hunnicutt), la médium mental Florence Tanner (Pamela Franklin) y el médium físico Benjamin Franklin Fischer (Roddy McDowall). Este último fue el único superviviente de una expedición anterior a la casa.

Uno de los elementos más destacados de la novela, y que la distingue de otras historias de casas encantadas, es su fisicidad. Incluso el mal que habita la casa tiene un componente muy físico; las amenazas se concretan, por ejemplo, con la violación por parte de un espectro de una de las protagonistas. Curiosamente, ese componente tan visual fue eliminado de la adaptación cinematográfica, titulada The Legend of Hell House (La leyenda de la casa del infierno, 1973) en la que el director John Hough optó por la sugerencia y la ocultación, en lugar de por la explicitación de la violencia física que aparece en la novela. Los motivos de este cambio sólo pueden ser objeto de especulación. La adaptación es de 1973, momento en el que la visualización de la violencia es más recurrente en el cine estadounidense y británico que en momentos anteriores, por lo que quizás el cambio obedece a una cuestión de estilo visual. $\mathrm{O}$ bien porque como nos recuerda Stephen King (2006: 174):

Lo que se oculta tras la puerta o acecha en lo alto de las escaleras nunca resulta tan aterrador como la puerta o la escalera en sí. Y a causa de ello se genera una paradoja: el trabajo de horror artístico casi siempre resulta decepcionante. Es la clásica situación en la que resulta imposible ganar. Puedes asustar a la gente con lo desconocido durante mucho, mucho tiempo [...] pero antes o después, como en el póquer, hay que mostrar las cartas.

Tanto la novela como su adaptación fílmica acaban enseñando sus cartas, aunque la versión de John Hough lo hace de manera muy discreta, sugiriendo más que mostrando la violencia física y el contenido sexual de la novela de Matheson. El propio autor declaró que esos elementos violentos estaban en el guión que él mismo escribió pero que fueron finalmente suprimidos, sin que sepamos si lo fueron en la fase de rodaje o el montaje final de la cinta (McGilligan, 2003: 210): 
La verdad es que [La leyenda de la casa del infierno] podría haber sido más terrorífica. Fueron demasiado discretos, la verdad. Mi libro es mucho más terrorífico. Escribí el guión, pero suprimieron determinadas partes; todo lo que era más visual. Como la escena en la que Pamela Franklin es violada por el fantasma; en mi libro, y probablemente también en mi guión original, contaba que lo que parecía un fantasma descendía sobre ella. Era espantoso. Decidieron no mostrar nada, y puede que hicieran bien. En esa película no se llegaba a ver nunca nada. Todo estaba sugerido.

Un estudio detallado del estilo visual de la película nos inclinaría a pensar que gran parte de esa violencia que sí contenía el guión nunca fue rodada. La película utiliza una planificación y una visualización muy propias del género de horror y fácilmente identificables: planos de situación contrapicados de la casa Belasco (exteriores), planos generales picados de las grandes estancias de la casa (interiores), utilización de grandes angulares para distorsionar la imagen, planos inestables y distantes que parecen mostrar el punto de vista de un ente superior (¿Belasco, su hijo, Daniel Belasco?), uso de los espejos para reflejar la imagen, alterarla o incluso invertirla. El repertorio de trucos visuales es amplio. En ocasiones su uso puede parecer muy tópico, aunque nos parece que John Hough acierta al intentar utilizar esta batería de recursos para transmitir una cierta inestabilidad física, geográfica, que afecta a la casa y que la convierte en un espacio de contornos imprecisos. Digamos que visualmente se nos transmite bien la idea de una casa que es más grande por dentro que por fuera y, por tanto, amenazadora e inquietante, ya que nunca llegamos a transitarla por completo. Tampoco lo harán los personajes, auténticos viajeros perdidos en un infierno físico y psíquico, en el que es más fácil encontrar la puerta de entrada que la de salida. Puede que sea precisamente ése otro de los elementos que definen el concepto de espacio en la obra de Matheson, un laberinto transitable y proteico que cambia de forma a cada nuevo paso que das. Parte de ese estilo visual ya había sido ensayado en $\mathrm{La}$ casa encantada (The Haunting), la película que Robert Wise rodó en 1963 adaptando la novela de Shirley Jackson que ya hemos mencionado. De hecho la visualización de planos deformados es una idea ya presentada por Wise, quien llegó a utilizar al efecto una nueva lente de Panavision que no estaba todavía en el mercado porque, precisamente, provocaba ciertas deformidades en la imagen. Esa idea visual, muy recurrente en el género, es utilizada también por Hough, como parte de una estrategia que pretende plegar el espacio sobre los personajes que habitan la casa en un intento de traducción visual del original literario y del guión escrito por Matheson. 


\section{TOPOGRAFÍAS DEL YO (EN UN INFIERNO MÓVIL)}

Hemos hablado de la importancia de la novela de Jackson para un Matheson que, con La Casa Infernal, adapta y utiliza algunos de los elementos básicos del American Gothic. Esa tradición se remonta, según Savoy (1998: 9), hasta el conocidísimo cuento de Edgar Allan Poe «La Caída de la Casa Usher». Eric Savoy analiza el cuento de Poe y otras obras inscritas en la tradición de los espacios góticos (encantados o no; hablamos de Nathaniel Hawthorne, Henry James, Stephen King o el Truman Capote de A sangre fría, entre otros) a partir de categorías freudianas. De entre las ideas de Freud aplicables al terreno de lo fantástico destacan la del retorno de lo reprimido y la categoría de lo «ominoso», que suelen utilizarse para analizar los vaivenes psíquicos que sufren los inquilinos de las casas encantadas. De la misma manera que una casa encantada demuestra tener una multiplicidad de espacios no explícitamente reconocidos en sus escrituras de compraventa, los moradores de estas casas acaban comprobando en carne propia lo extenso que puede ser el reino de lo inconsciente y lo fácil que va a resultar para fuerzas demoníacas de diversa índole encontrar la puerta de acceso a la mente y los cuerpos de sus víctimas. ${ }^{8}$

Si bien no todas las casas se comportan de la misma manera, ni todos los inquilinos sufren los mismos problemas, sí podemos ver que hay una cierta continuidad en la manera de entender esos espacios tan particulares muy propios de la tradición del American Gothic. Y curiosamente, por mucho que la casa ideada por Poe sea la considerada casi unánimemente como la primera casa encantada de cierta relevancia, haríamos bien en puntualizar algunos aspectos. El cuento de Poe, «La caída de la casa Usher», es voluntariamente elusivo respecto a los motivos últimos por los que la casa se hunde en el pantano y encuentra su final. Sabemos que la decadencia y la enfermedad se ha adueñado de sus últimos moradores -los hermanos Roderick y Madelinepero no se nos explicita maldición alguna, ni se identifica fuerza sobrenatural concreta que actúe sobre la casa. En este punto Poe se muestra enigmático y esquivo, de manera que el lector se ve forzado a elaborar numerosas hipótesis sobre las causas últimas del derrumbe.

Por el contrario, son muchos los ejemplos de casas encantadas que siguen un esquema ligeramente diferente. La amenaza queda perfectamente

8 No deja de ser curioso que Freud pensara la estructura de la mente humana de manera estratificada y que, necesariamente, de ello pueda deducirse una metáfora sobre las partes visibles y superiores y las partes ocultas y enterradas. Esa metáfora es espacial y hasta nos permite hablar de un mapa de la mente, una idea artísticamente muy fructífera. 
identificada como una fuerza demoníaca sobrenatural, oculta e intermitente, que se manifiesta en los diferentes hechos y actos malvados cometidos en esa misma casa tiempo atrás. Estamos ante un motivo que ha dotado de gran fuerza a estos ejemplos del American Gothic, y que se estructura claramente desde el clásico seminal de Shirley Jackson hasta la obra de Matheson que aquí nos ocupa. Los procesos que se suceden en estos espacios son parecidos y, hasta cierto punto, siguen un mismo esquema rígido. Se inician con la llegada de nuevos inquilinos a una casa que arrastra un historial dudoso que, no obstante, no sirve de aviso a los atrevidos moradores. Continúa con unas primeras manifestaciones sobrenaturales que son vistas por los sujetos afectados (no suelen ser todos los moradores de la casa) como algo imposible achacable a sus errores de juicio; acaba finalmente con la posesión de la persona por parte de esas fuerzas demoníacas. El esquema de latencia-manifestación-posesión es el más típico y utilizado por las historias de casa encantada y encaja perfectamente con La Casa Infernal. También ocurre con las explicaciones que finalmente pueden darse al fenómeno de la casa encantada. Estos espacios suelen estar malditos porque en ellos se han cometido actos atroces de maldad, violando, se diría, las leyes humanas y divinas. Ante tanta maldad los espíritus moran sin descanso, y esos espíritus son auténticas fuerzas demoníacas dispuestas a poseer como venganza a los nuevos inquilinos del lugar. Pero no a todos, sino sólo a unos pocos, por mucho que otros puedan ver y apreciar los efectos de su presencia y acción. ${ }^{9}$

Es interesante comprobar cómo se producen dos movimientos críticos en paralelo, interrelacionados en cierta manera. Conforme la investigación sobre las complejidades de la mente humana aumenta y se empiezan a describir enfermedades mentales que darían una explicación racional a muchos sucesos aparentemente sobrenaturales, las investigaciones sobre dichos fenómenos que rompen con toda lógica científica también aumentan exponencialmente. El contraste se hace más profundo, la disonancia cognitiva se refuerza conforme la ciencia descarta muchos casos sobrenaturales dudosos o directamente falsos. Pero los que resisten el análisis científico se vuelven más aterradores si cabe. Por ello Matheson concibe La Casa Infernal como un informe científico, ambientado además en 1970. Como sabemos el autor ya había ensayado el tema de las casas encantadas en relatos anteriores, el más conocido de los cuales es «La Casa Slaughter».

9 Este esquema narrativo es muy parecido al que Noël Carroll expone en su imprescindible Filosofía del terror o paradojas del corazón. Carroll habla de la «trama del descubrimiento complejo» y la divide en cuatro fases: presentación, descubrimiento, confirmación y enfrentamiento (2005: 212). 
Aparecido originalmente en la revista Weird Tales (julio de 1953), en él se narra la historia de una casa encantada y de sus dos inquilinos, dos hermanos en este caso. El relato adquiere la formulación de un extenso informe que uno de los hermanos escribe y envía a la Sociedad Rand para las Investigaciones Psíquicas. A modo de informe, el autor explica con detalle cómo las fuerzas sobrenaturales se adueñan de su hermano y cuál es el precio que pagan por no haber escuchado las advertencias transmitidas a los dos hermanos en forma de habladuría local. En La Casa Infernal se utiliza la forma narrativa del informe reforzado con una datación de los hechos muy estricta. Las discusiones científicas, ausentes como tales en el relato «La Casa Slaughter», están muy presentes en La Casa Infernal, y en muchas ocasiones se relacionan, precisamente, con el terreno de lo psíquico. En el tramo final de la novela, Barrett y Edith discuten sobre el comportamiento de la médium Florence y sobre su posible posesión por parte de una fuerza sobrenatural. Barrett niega la posibilidad de que Florence esté poseída por Daniel Belasco ni por nadie, «a no ser que se trate de su yo interno, de su verdadero yo, de su yo reprimido [...] Un médium es una persona muy inestable [...] Cualquier psíquico que merezca ese nombre es, invariablemente, una persona histérica o sonámbula, una víctima de la conciencia dividida» (Matheson, 2012: 236). Esta explicación, que no convence a Edith por haber experimentado ella misma una alteración similar que no achaca a ningún deseo reprimido, explicita bien el choque entre la racionalidad científica y el fenómeno sobrenatural. En este caso Barrett utiliza categorías freudianas para explicar un comportamiento inusual. Como buen científico, Barrett intenta delimitar lo que puede ser explicado por la ciencia incluyendo en su esfera de influencia tantos elementos como sea posible.

La obra que nos ocupa exhibe otro tema importante y que ha sido tratado en obras posteriores, algunas de las cuales toman como evidente punto de partida las aportaciones de Matheson -como es el caso de la reciente e interesante película Expediente Warren (The Conjuring, James Wan, 2013)-. La constante interacción entre espacio físico y sujeto estructura una parte importante de las obras de Matheson, y muy particularmente La Casa Infernal. Los sujetos que pueblan sus ficciones se ven constantemente alterados y reconfigurados por un espacio cambiante, móvil, de contornos imprecisos y habitualmente asediado por elementos sobrenaturales. Los espacios cotidianos se vuelven amenazantes y, en varios casos, auténticas prolongaciones del infierno (algo que, por otro lado, tiene un correlato en el pensamiento de Matheson; él mismo se define como un creyente). 
El espacio infernal sería así un espacio en el que, por definición, es fácil adentrarse aunque muy difícil escapar, puesto que nunca tiene unos límites definidos, cambia de forma, nunca vemos su punto de origen ni final. El protagonista de I Am Legend (Soy leyenda, 1954) habita un entorno gigantesco, imposible de explorar, en el que existen zonas en las que es mejor no adentrarse por ser dominio exclusivo de los vampiros; para el de The Shrinking Man (El hombre menguante, 1956) el entorno cotidiano se convierte en un auténtico infierno doméstico en el que todo se vuelve amenazante. En Bid Time Returns (En algún lugar del tiempo, 1975) el protagonista, Richard Collier, aquejado de un tumor cerebral, inventa un sistema mediante el que puede proyectar su mente y viajar al pasado, con el consiguiente riesgo de quedarse atrapado y perdido en la línea temporal. En este caso tiempo y espacio se combinan en una historia muy centrada en las relaciones amorosas entre los personajes. La ambientación de estas historias es variada, desde futuros distópicos a presentes marcados por la amenaza nuclear, pero todas coinciden en algo. La entidad más inestable de cuantas podamos asociar a estas historias es el yo, enfrentado a espacios y tiempos que le superan, amenazado por el cambio constante, por elementos fantásticos o por tecnologías aterradoras. En resumen, ese yo choca frontalmente con una ausencia que, como hemos comentado al inicio, contiene siempre un margen de indefinición, un elemento que no puede explicarse por completo de manera racional y cartesiana. Esta idea encaja bien con el tiempo en el que se escriben parte importante de las obras de Matheson que hemos citado aquí. Un momento en el que se estaba definiendo lo que Irving Malin llamó «el nuevo gótico americano». Este periodo, que abarcaría los veinte años posteriores a la publicación de The Haunting of Hill House, fue también estudiado por John G. Park. Ambos autores sugieren que el Nuevo Gótico Americano utiliza las casas encantadas para simbolizar «no intereses sexuales y el temor al sexo, sino el interés en el yo y el temor a uno mismo [...] Y en una sociedad como la norteamericana, sumida en el trance cada vez mayor del yoísmo, no debería sorprendernos que el género del horror haya recurrido cada vez más a mostrarnos un reflejo que no nos gusta: el nuestro» (King, 2006: 408-409). Así que el mal tiene finalmente un rostro y es el nuestro. Esos personajes sumidos en infiernos cotidianos, enfrentados a los demonios de la casa Belasco, a los vampiros del mañana o a la energía atómica se enfrentan finalmente a un problema mucho más irresoluble que un laberinto cambiante: se enfrentan a un yo inestable y desarticulado habitante de espacios de indefinición. Quizás por este motivo el protagonista de Soy Leyenda, Robert Neville, llega a la conclusión de que su única oportunidad es 
desaparecer, morir tras haberse convertido en algo tan malvado como los vampiros que ha perseguido.

\section{BiBLIOGRAFÍA}

Carroll, Noël (2005): Filosofía del terror o paradojas del corazón, Antonio Machado Libros, Madrid.

Cavell, Stanley (1979): The World Viewed: Reflections on the Ontology of Film, Harvard University Press, Londres.

Damasio, A. (2005): En busca de Spinoza, Crítica, Barcelona.

DeACon, Terrence W. (2013): Naturaleza incompleta. Cómo la mente emergió de la materia, Tusquets, Barcelona.

Hofstadter, Douglas R. (2008): Yo soy un extraño bucle, Tusquets, Barcelona.

KING, Stephen (2006): Danza Macabra, Valdemar, Madrid.

Malin, Irving (1962): New American Gothic, Southern Illinois University Press, Carbondale.

Matheson, Richard (2011): La Casa Infernal, Minotauro, Barcelona.

McGilligan, Pat (2003): Backstory 3. Conversaciones con guionistas de los años 60, Plot Ediciones, Madrid.

PARK, John G. (1978): «Waiting for the end: Shirley Jackson’s The Sundial», Critique, vol. XIX, núm. 3.

<http:/ /dx.doi.org/10.1080/00111619.1978.10690174>

Roas, David (2011): Tras los límites de lo real. Una definición de lo fantástico, Páginas de Espuma, Madrid.

SAvor, Eric (1998): «The face of the tenant: A theory of American Gothic», en Robert K. Martin y Eric Savoy, American Gothic. New Interventions in a National Narrative, Iowa University Press, Iowa.

Walters, James (2011): Fantasy Film. A critical introduction, Berg Publishers, Oxford. 